Short Communication

\title{
Incorporating Oxygen CoP Nanosheets: Facile Synthesis and Application for Supercapacitor Electrodes
}

\author{
Jia Wang, Xuan Ren, Liang Chen, and Baocheng Wang ${ }^{*}$ \\ Taiyuan University of Technology, Taiyuan, Shanxi, P.R.China \\ *E-mail: tylgdwangjia@sina.com
}

doi: $10.20964 / 2018.11 .78$

Received: 4 |august 2018 / Accepted: 16 September 2018 / Published: 1 October 2018

\begin{abstract}
As an effective way, surface functionalization can modulate the electrochemical properties of nanomaterials for supercapacitors. The $\mathrm{Co}_{3} \mathrm{O}_{4}$ nanosheets as the precursor have been synthesized using a solvothermal reaction followed by a high-temperature calcination reaction. Oxygen-incorporating CoP nanosheets were obtained via a high-temperature phosphating reaction. The obtained samples have been characterized by X-ray diffraction and transmission electron microscopy. The electrochemical results displayed that the oxygen-incorporating $\mathrm{CoP}$ nanosheets are promising anode material for high-performance supercapacitor devices. The specific capacitance of the sample could be calculated to 416,345 and $317 \mathrm{~F} \mathrm{~g}^{-1}$ at a current density of 2, 5 and $10 \mathrm{~A} \mathrm{~g}^{-1}$, respectively. Even after 900 cycles, the capacitive retention of the oxygen-incorporating CoP nanosheets electrode was $97 \%$ and it remained unchanged, manifesting that such a supercapacitor displays a good electrochemical cycling stability. The high specific capacity, long cycle stabilities as well as great rate capability make the oxygen-incorporating CoP nanosheets a good candidate for high-performance supercapacitors.
\end{abstract}

Keywords: CoP nanosheets, Oxygen incorporation, Supercapacitors, Polymers, Electronic materials

\section{$\underline{\text { FULL TEXT }}$}

(C) 2018 The Authors. Published by ESG (www.electrochemsci.org). This article is an open access article distributed under the terms and conditions of the Creative Commons Attribution license (http://creativecommons.org/licenses/by/4.0/). 